Vol. 5, No. 3-4, 2019

\author{
Andrii Slipchuk ${ }^{1}$, Andrii Kuk ${ }^{2}$, Yaroslav Kusyi ${ }^{3}$ \\ 1. Department of Mechanical Engineering, Lviv Polytechnic National University, \\ Ukraine, Lviv, S. Bandery Street 12, E-mail: andrii.m.slipchuk@lpnu.ua, ORCID 0000-0003-0584-6104 \\ 2. Department of Mechanical Engineering, Lviv Polytechnic National University, \\ Ukraine, Lviv, S. Bandery Street 12, E-mail: andrii.m.kuk@lpnu.ua, ORCID 0000-0001-9145-243X \\ 3. Department of Mechanical Engineering, Lviv Polytechnic National University, \\ Ukraine, Lviv, S. Bandery Street 12, E-mail: jarkym@ukr.net, ORCID 0000-0001-5741-486X
}

\title{
MODELING OF “COMBINED CUTTER - CONE” CONNECTION IN TRICONE DRILL BITS
}

Received: October 25, 2019 / Revised: December 22, 2019 / Accepted: December 28, 2019

C Slipchuk A., Kuk A., Kusyi Ya., 2019

\begin{abstract}
A theoretical analysis of the stiffness of the "cutter-cone" connection was performed. In the article the character and magnitude of the tension at the contact of "cutter-cone" are investigated. An analysis of the surface of the openings for carbide inserts revealed traces of plastic deformation and fretting wear. Since the contact bond of the cutter with the body of cone is the only factor that provides the strength of the connection, let consider the effect of mechanical properties of the cones body and a cutter on the magnitude of the forces of contact and tension in the connection. The surface of the shaft of this design consists of equal parts of solid alloy and steel. If you make a ring at a smaller diameter of the shank of a carbide cutter, this will increase the reliability of the connection of the insertion with the body of the rock cutting tool, optimize toughness of cutter fastening, and ensure high stability of the hard-alloyed inset cutter before fracture.

As a result of the conducted researches, a qualitative correlation between the hardness of the carbide insertion fastening in the holes of cone and the nature of the destruction of the carbide cutters has been established. Due to the conducted research, the character of the distribution of contact tensions in the conjugated areas "combined cutter - a hole of cone" was established. The theme of the development of new rational constructions of rock-destructive equipment of cones, rock-destructive inserts, schemes of its effective arrangement on the brushes of cone is still actual. A separate issue of further research is the study of functional and energy interaction of elements of propulsion and rock-destructive equipment.
\end{abstract}

Keywords: insertion cutter, reliability, cone, strength, tricone drill bits, combined cutter, tension, joints, modeling.

\section{Introduction}

Extremely difficult conditions of the work of rock-destructive equipment require the use of special materials, ensuring the strength of cutter, reliable attachment of the cutter in the body of cone.

One of the main factors of the productive life of cones is the nature of fixing hard-alloyed cutters. It determines the performance of drill tricone drilling bits. In world practice, it has become a tradition to constantly expand the range of drill tricone drilling bits. This also applies to the insertion of rockdestructive equipment. However, the high price of the material of the insertion cutter forces us to search for other combined structures [1]-[3]. Such decisions, as a rule, required significant and even radical changes. It is necessary to change the technology of manufacturing the roller drills.

During the past decades, there has been a tendency to minimize time and resources. Modern knowledge-based approaches are used in the technology of oil and gas engineering. In the manufacture of roller tricone drills they are implemented during design and technological training. Functional-oriented 


\section{Modeling of "Combined Cutter - Cone" Connection in Tricone Drill Bits}

technology of manufacturing of rock-destructive equipment is applied. This requires studying the methods for ensuring the strength of conjugation "combined cutter - cone". Therefore, the establishment of rational parameters for the construction of shaft drill bits with carbide inserts is an urgent problem and has an important practical significance for the tricone drilling bit construction.

\section{Main part}

In recent years, there have been several attempts to solve the problem. This is reflected in scientific papers [4]-[8]. In particular, the destruction of the "cutter-cone" connection in related with the strength of the steel shaft was investigated [4]-[8], the structure of the coupling of the hole and the shaft of the carbide insert [9] was analyzed, and the influence of the tension value in the joint was designated [10].

Low strength indexes of steel cones limit the amount of permissible tension. There is a danger of cracks and a slice of the material layer in the hole, which causes the hard-alloyed inset cutter to fall out [10]. At high values of the boundary of steel cone, there is an edge effect. The concentration of tensions in the area of the "hole of the cone - outer band" causes the risk of cracks in the edges of the opening.

In the case of a high degree of brittleness of the cones material, fragmentation of the wreaths and cutters was observed (Fig. 1). The nature of the destruction of carbide insert cutters turned out to be different. This is due to the suboptimal tension in the conjugation of the "cutter-cone" connection [10].

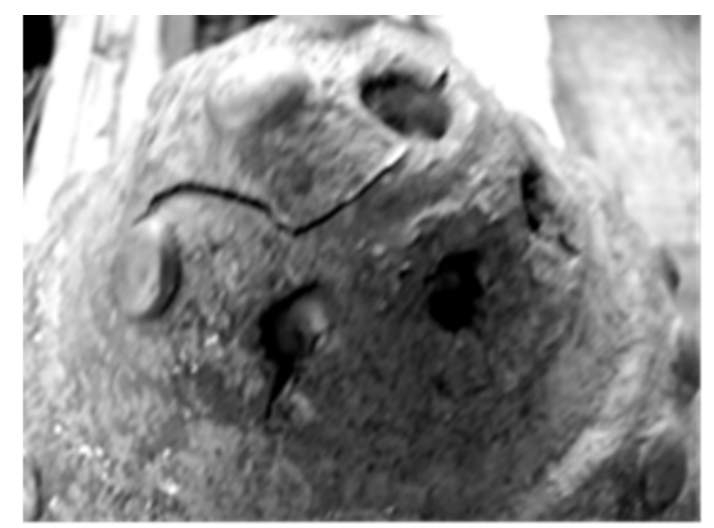

Fig. 1. Macro cracks in the area of the top of the cone and the fall of hard-alloyed cutters

It is possible to change the stress state in the contact area of the "cutter-cone" connection [10]. If you change and improve the design of the shank of a hard alloy rock-destructive insert, then you can increase the reliability of the connection.

There are attempts to change the design of the shank of cutters. They were offered to solder or flood it with liquid steel in the body of the cone [1], [2]. This method of soldering hard-alloyed teeth did not find application in the manufacture of large diameter tricone drilling bits, because no significant effect was obtained.

A theoretical analysis of the stiffness of the "cutter-cone" connection was performed [4]. The authors predict an increase in the efficiency of the connection by increasing the length of the part of fused cutter. However, at the same time, the dimensions of the support node will inevitably increase. In the calculation model it is assumed that the oscillations are carried out without resistance. The contact layer has only elastic properties, and the cone is rigid.

The authors [10] proposed to connect the "cutter-cone" by fusing. It is based on the wetting of the surface of cutter with metal of cone. The contact area is dissolved. There is a mutual diffusion with the subsequent formation of a solid bond. There are given dependences, which allow to determine the tension in a carbide soldering cutter (on a deposited layer and metal of cone). For comparison, the stress-strain state of connection with the tension of the "cutter-cone" was considered. The authors operate with mean values of tensions. We obtained results of the relations of normal $\sigma_{r}$ and tangential $\sigma_{\tau}$ tensions in cylindrical bodies. However, in the area of the contact zone of the "cutter-cone" connection there are radial-compressed $\sigma_{r}$, tangential $\sigma_{\tau}$ and longitudinal axial tensions $\sigma_{z}$. 


\section{Andrii Slipchuk, Andrii Kuk, Yaroslav Kusyi}

The western chamfer parameters are set to reduce the probability of fractures. The injection of such carbide inserts into the holes of the drilling tool will reduce its destruction.

Recommendations for degreasing the conjugate surfaces of the insert and the hole which are necessary for better adhesion are proposed [10].

In the article the character and magnitude of the tension at the contact of "cutter-cone" are investigated. It occurs in the tricone drilling bit during the work. It is explored the character of the correlation between the structural features of the shank of rock-destructive inserts and the tensioned state in the conjugated parts.

An analysis of the surface of the openings for carbide inserts revealed traces of plastic deformation and fretting wear. In all cases, in the area of the exit of cutter from the cones hole, visible areas of frailty with a perfectly clean surface and traces of slander were discovered. Somewhere there were cracks. The most pronounced contact area in the landing "cutter-cone" is found in the upper and lower parts of the surface of hole. Here is the most noticeable plastic deformation in the form of a dent from the edge of the shank (Fig. 1). This can be explained by the considerable stiffness of the system "cutter - cone - face". So, there is a loosening of the hard-alloyed inset cutter in the cones hole during the operation of the tricone drilling bit [10].

The most promising way is to reduce the stiffness of the working system "rock - cutter - cone". This will help to improve the tension in the cutter and cone [10]. It has a positive effect on the durability of hard-alloy equipment of drill tricone drilling bits.

Therefore, the task is:

- to study the nature of the tensioned state of a new construction of a shaft of the insert carbide rigging of tricone drill tricone drilling bit (the construction of a rock-destructive insert, described in [9]);

- to optimize the rigidity of the system "rock - cutter - cone".

Today, according to the technological process of assembling drill cone tricone drilling bits in the connection of "cutter-cone", the working tension should be within $N_{\min }=0.081 \mathrm{~mm}$ and $N_{\max }=0.144 \mathrm{~mm}$.

The surface of the shaft of this design consists of equal parts of solid alloy and steel. If you make a ring at a smaller diameter of the shank of a carbide cutter, this will increase the reliability of the connection of the insertion with the body of the rock cutting tool, optimize toughness of cutter fastening, and ensure high stability of the hard-alloyed inset cutter before fracture. That is, the ring acts as a buffer. This simultaneously increases the strength of the press joint and reduces the stiffness between the body of rock cutting tool and the hard-alloyed cutter.

For experimental research, bench testing of cone tricone drilling bit standard roller cone bits with experimental cutters was carried out (Fig. 2). The cutter is made of an alloy WCo10, for which $\sigma_{T}=1900 \mathrm{MPa}$. Cones and rings of cutters shaft are made of steel $14 \mathrm{NiCrMo1-3-4}$, for which $\sigma_{T}=900 \mathrm{MPa}$. An experiment was carried out. To compare the assessment of the efficiency of cutters were set alternately (through one). On one tricone drilling bit cones were placed with different types of fixing the cutters: the proposed design and standard one.

The tricone drilling bit test was carried out on a metal van from C1020 with an axial load of $220-250 \mathrm{kN}$ and a tricone drilling bit speed of rotation $60-75 \mathrm{rpm}$. Such conditions imitated the real conditions of the tricone drilling bit work (Fig. 2).

Since the contact bond of the cutter with the body of cone is the only factor that provides the strength of the connection, let consider the effect of mechanical properties of the cones body and a cutter on the magnitude of the forces of contact and tension in the connection.

The depth of the fit of experimental cutters and the created 3D model was $10 \mathrm{~mm}: 5 \mathrm{~mm}$ - the height of the steel ring, which is secured to the hard alloy part of the shank with smaller diameter, other $5 \mathrm{~mm}-$ the height of the hard alloy part of the shank with larger diameter. Some part of this depth belongs to the body of rolling-cutter teeth row. The largest part in which there is the steel ring - to the body of cone. The rolling-cutter teeth row has a lug on cones body and has close free facet. The stressed state of the rollingcutter teeth rows body and the scarves will be different from each other (Fig. 3). 


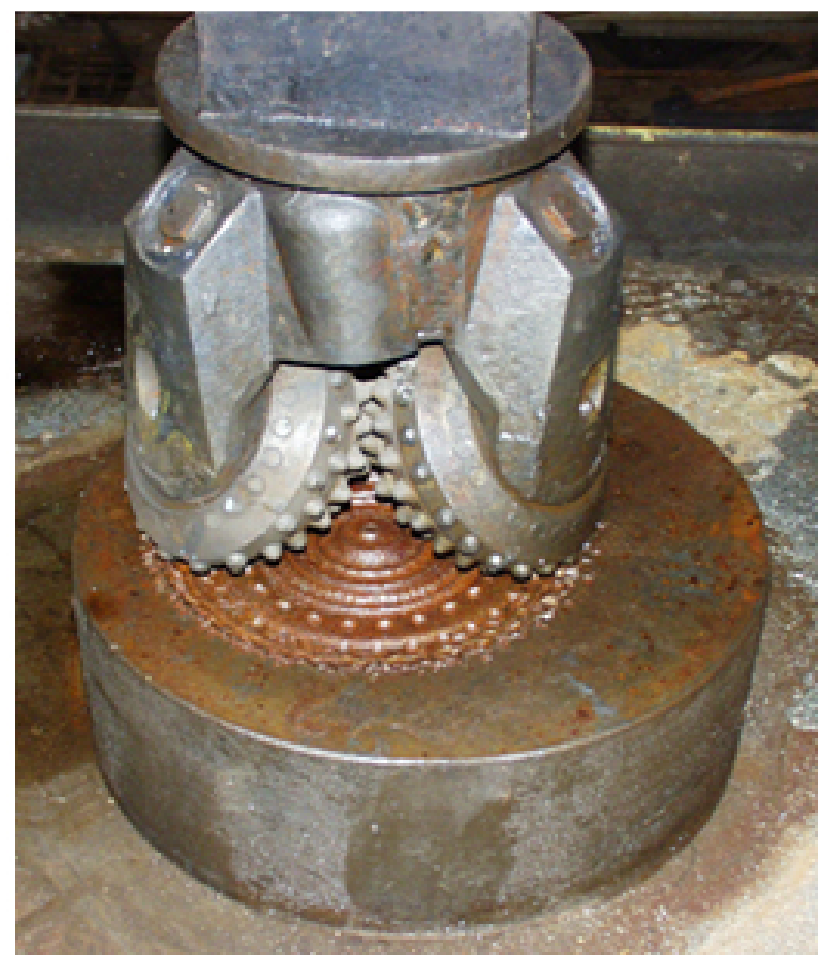

Fig. 2. General view of the tricone drilling bit with experimental rock-destructive inserts after working 8 hours in the stand conditions

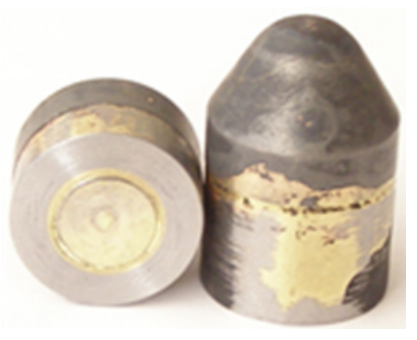

a

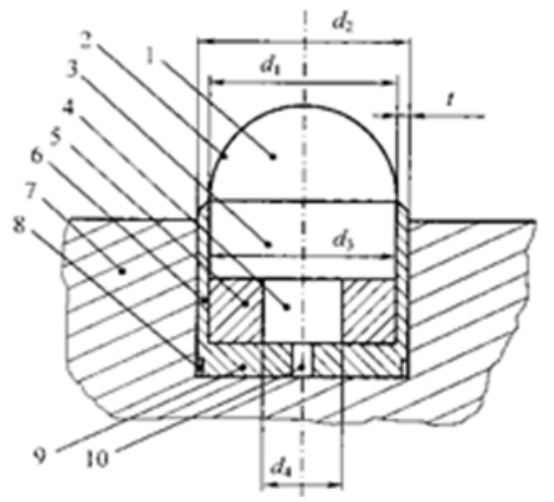

b

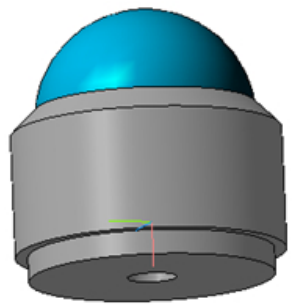

c

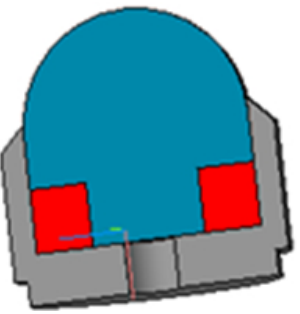

d

Fig. 3. General view (a), schematic design of construction (b), 3D model of the rock-destructive insert (c), section 3D model of the rock-destructive insert (d) according to: 1 - carbide element (cutter); 2 - working head; 3 - shaft diameter with larger diameter; 4 - shaft diameter with smaller diameter; 5 - ring, 6 - intermediate shaft-collar;

7 - tool case socket; 8 - cylindrical spindle; 9 - bottom of the intermediate shaft-collar; 10 - central hole

When fit with a tension, the contact pressures are determined by known Lamé's equation. The pressure in the contact area of the cutter with the body of the cone is expressed by the formula:

$$
p_{k}=\frac{N}{d_{i}}\left(\frac{1-\mu_{i}}{E_{i}}+\frac{1+\mu_{c}}{E_{c}}\right)^{-1},
$$

where $d_{i}$ - diameter of the cutter $(15.28 \mathrm{~mm}) ; N$ - tension value when planting a cutter in a cone $(\mathrm{mm})$; $\mu_{i}$ - Poisson's coefficient for shank material (for a steel ring - 0.3, for a solid alloy -0.24 ); $\mu_{c}$ - Poisson's coefficient (for the material of cone -0.3 ); $E_{i}$ - elastic modulus for material of cutter's shank (for a shaft hard-alloy shank $-5.6 \cdot 10^{5} \mathrm{MPa}$, and for a shanks steel ring $-2.1 \cdot 10^{5} \mathrm{MPa}$ ); $E_{c}$ - elastic modulus for material of cone $-2.1 \cdot 10^{5} \mathrm{MPa}$. 


\section{Andrii Slipchuk, Andrii Kuk, Yaroslav Kusyi}

In the contact area in the cones body and in the body of cutter there are radial compressions $\sigma_{r}$, tangential $\sigma_{\tau}$ and longitudinal axial tensions $\sigma_{z}$.

It must be considered that $\left[\sigma_{P}\right]_{u}<\left[\sigma_{P}\right]_{3}$. In the body of cone around the conjugation there is a strain beyond the boundary of fluidity. The tension value should be substantiated to prevent cracking. Consequently, the contact pressure at the height of the projection of the rolling-cutter teeth row (1) will be established:

$$
p_{k}(l)=\frac{N}{d_{3}}\left(\frac{1-\mu_{3}}{E_{3}}+\frac{\frac{l^{2}+d_{3}}{l^{2}-d_{3}}+\mu_{u}}{E_{u}}\right)^{-1} .
$$

According to the carried out researches, we will now analyze the strength of the cones tricone drilling bit with an improved design with a diameter of $302 \mathrm{~mm}$. It has a consolidated force. It is applied to the main hard-alloyed inset cutter of the model and equals $28 \mathrm{kN}$. We simulate such case (Fig. 4):

- on each cutter of the main one - apply $25 \mathrm{kN}$ on.

- simulate a contact area with three cutters. Such quantity falls on obliteration.

The study area is a plot of 3 cutters. Each of the mentioned cutter accounted for $25 \mathrm{kN}$ [9].

In general, in the contact zone, the cutters were under a load of up to $80 \mathrm{kN}$ [9]. In addition, there is a pressure taken from the tension of landing "shank of cutter - insert - hole of cone" - $114 \mathrm{MPa}$. The results of investigations the character of tensioned state in the wreaths of the cone are given in Figs. 5 and 6.

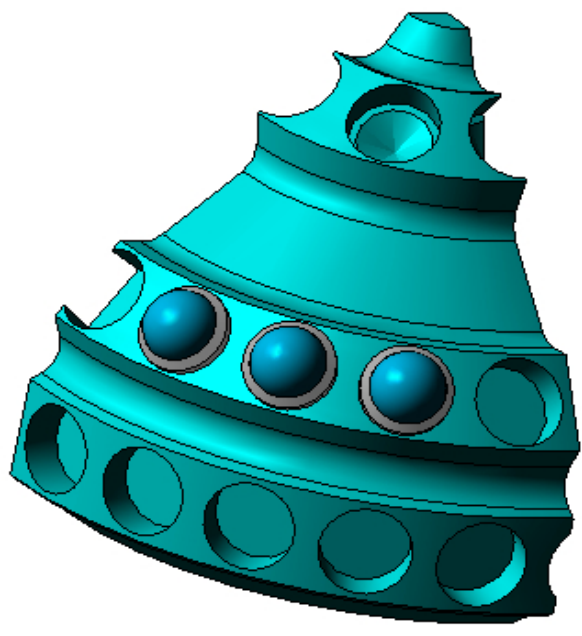

Fig. 4. 3-D segment of a cone of roller tricone drill with diameter of $302 \mathrm{~mm}$ without force

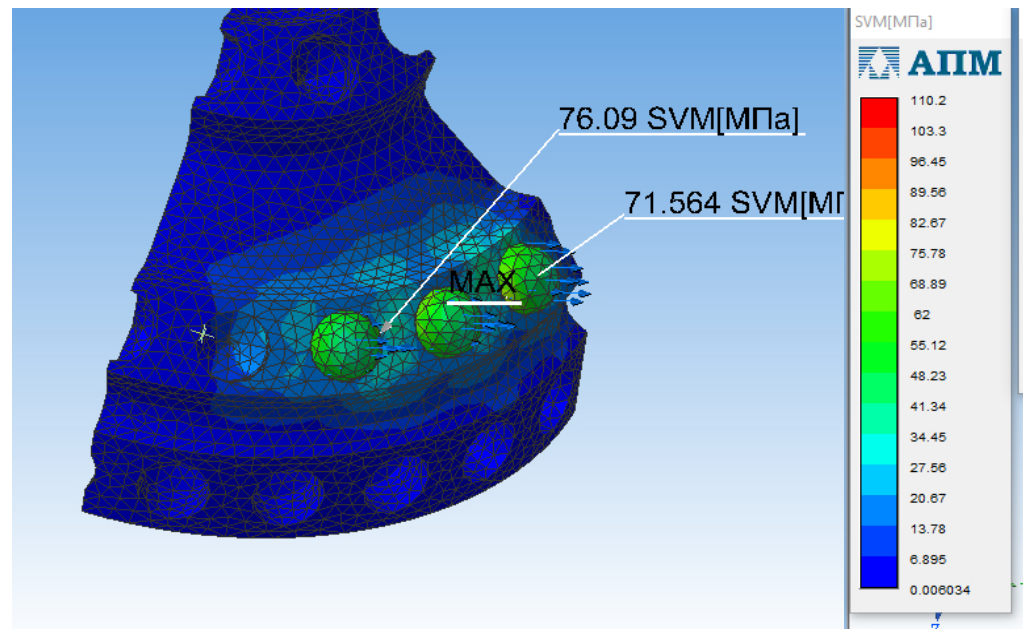

Fig. 5. Simulation of a tensioned state in the areas of conjugation "shank of a cutter - a hole of cone" on the rolling-cutter teeth rows of cone of a drill tricone drilling bit with a diameter of $302 \mathrm{~mm}$ without shaft-collar

After the performed research, we can see (in Figs. 5, 6) that the most tensioned place will be the part of the cutter (Fig. 7). The contact tensioned on the cutter can reach more than $50 \mathrm{MPa}$ when three elements "cutter - insert - cone" interact together. We have the distribution of these tensions on the conjugated surfaces. The intermediate shaft-collar has very important role of an additional compensator. It begins to deformation during compression, but provides a reliable contact between the insertion shank and the body of cones rolling-cutter teeth row. The role of shaft-collar as a compensator is well illustrated in Fig. 7. The contact area is an edge on the cone around the cutter.

As a result of the conducted researches, a qualitative correlation between the hardness of the carbide insertion fastening in the holes of cone and the nature of the destruction of the carbide cutters has been established. Namely, the contact area of the conjugated surfaces and the tensioned state in the joint determine the durability of the carbide cutter. 


\section{Modeling of "Combined Cutter - Cone" Connection in Tricone Drill Bits}

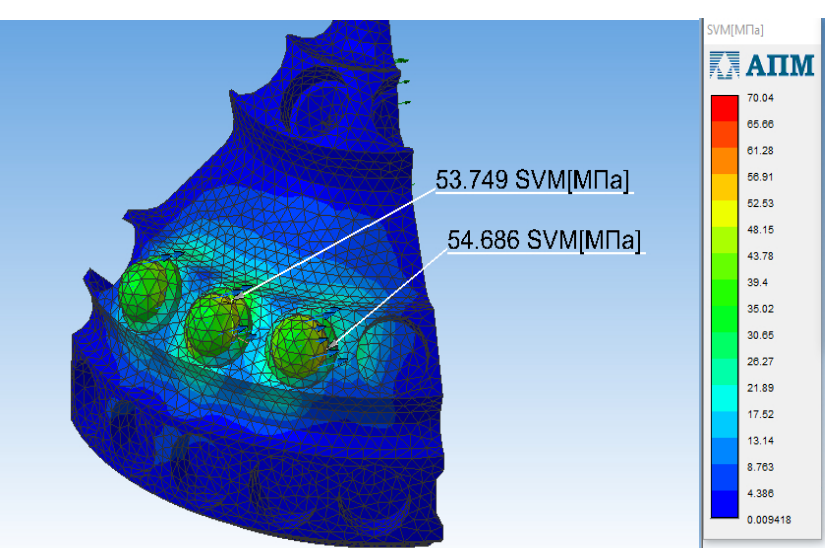

Fig. 6. Simulation of a tensioned state in the areas of conjugation "shank of a cutter - a hole of cone" on the rolling-cutter teeth rows of cone of a drill tricone drilling bit with a diameter of $302 \mathrm{~mm}$ with shaft-collar

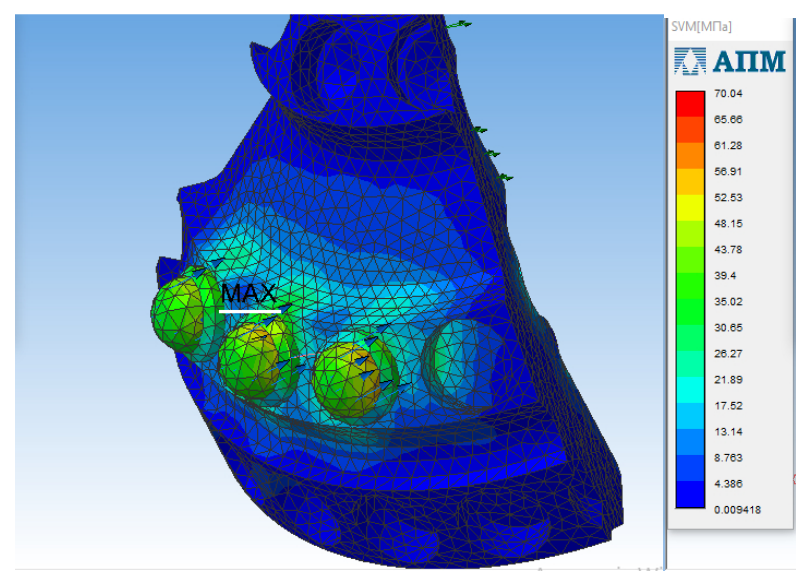

Fig. 7. Figure of the most tensioned areas of a cone

\section{Conclusions}

Due to the conducted research, the character of the distribution of contact tensions in the conjugated areas "combined cutter - a hole of cone" was established. For the first time their graph-analytical estimation is shown visually (Figs. 6 and 7). The rational parameters of the erosion insertion constructions are established. Applying the extrapolation of the results you can choose different sizes of inserts. The modeling and analysis has established a favorable distribution of the tensions state in a dangerous section of the surface of the hole in the cone's rolling-cutter teeth row. The analysis (with an optical magnification of 20 times.) did not detect the control sites of micro cracks in the conjugated surfaces. They could be in serial tricone drilling bits. The use of rock-destructive inserts simplifies and reduces the technology of making cones. That is, the need to protect the rolling-cutter teeth rows from cementation (which in this case is harmful), additional treatment of holes (deployment, calibration, floor polishing) disappears. Simulation of the drilling process brought the performance of the new rock-destructive equipment. It provides increased reliability of the connection "cutter - cone". Optional inserted insert element has allowed shifting the tensest place from the cylindrical edge of the cone to the cutter. All of this provides a higher cracksman ship due to better use of physic-mechanical characteristics of the material [10]. Testing of cones of the improved design in the stand conditions confirmed the effectiveness of the resulting insertion rock-destructive equipment of cones [10]. The experiment was carried out on a metal face.

The character of the distribution of the tensioned state in the connection "combined cutter - cone" is established. The efficiency of the use of structures for the insertion of rock-destructive equipment is substantiated. It is realized the effect of rational distribution of values of tensions throughout the length of the conjugate surface. This ensures not only the high reliability of the inserted rock-destructive equipment, but also significantly simplifies the technology of manufacturing holes in cones for hard-alloy equipment. The rational values of tension at the planting of solid-alloyed cutters with a combined shank in the body of cone are established. All of this is easy to extrapolate to other standard sizes of rock-destructive inserts.

The results of modeling and calculating the tensioned state in the connections confirmed that increasing the stiffness of the connection can be reached due to increase of tension force or by reducing the strength of the stock. It has also been proved that creating favorable conditions for conjugation can be achieved by using the most homogeneous materials (in this case, "steel - steel").

The theme of the development of new rational constructions of rock-destructive equipment of cones, rock-destructive inserts, schemes of its effective arrangement on the brushes of cone is still actual. A separate issue of further research is the study of functional and energy interaction of elements of propulsion and rock-destructive equipment. 


\section{Andrii Slipchuk, Andrii Kuk, Yaroslav Kusyi}

\section{References}

[1] A. Slipchuk, and A Kuk, "Evaluation of the permissible moment in a roller cone drill bit providing the prescribed reliability of work", Ukrainian Journal of Mechanical Engineering and Materials Science, vol. 4, no 1, pp. 116-124, 2018. [in Ukrainian].

[2] K. Bybee, "Drilling Performance of an Energy-Balanced Roller-Cone Bit", Journal of Petroleum Technology, vol. 12, pp. 49-50, 2003.

[3] J. D. Schroder, "Cone Retention and Tapered Bearing Preload System for Roller Cone Bit", US patent US20130105229A1, May 2, 2013.

[4] Z. Huang, Q. Li, Y. Zhou, S. Jing, Y. Ma, W. Hu, and Y. Fan, "Experimental research on the surface strengthening technology of roller cone bit bearing based on the failure analysis", Engineering failure analysis, vol. 29, pp. 12-26, Apr. 2013.

[5] S. Naganawa, "Feasibility study on roller-cone bit wear detection from axial bit vibration", Journal of petroleum science and engineering, no. 82-83, pp. 140-150, 2012.

[6] E. I. Kryzhanivs'kyi, R. S. Yakym, L. E. Shmandrovs'kyi, and Yu. D. Petryna, "Contact fracture of rolling bodies of open bearings of three-cone rock bits in aqueous environment", Materials science journal, vol. 46 (5), pp. 607-612, 2011.

[7] Y. Deng, M. Chen, Y. Jin, Y. Zhang, D. Zou, and Y. Lu, "Theoretical and experimental study on the penetration rate for roller cone bits based on the rock dynamic strength and drilling parameters", Journal of natural gas science and engineering, vol. 36, pp. 117-123, 2016.

[8] A. Nabilou, "Effect of Parameters of Selection and Replacement Drilling Bits Based on Geo-Mechanical Factors: (Case Study: Gas and Oil Reservoir in the Southwest of Iran)", American Journal of Engineering and Applied Sciences, vol. 9, no. 2, pp. 380-385, May, 2016.

[9] A. Slipchuk, and Y. Datsishin, "Improving the quality technology pressing of tungsten carbide inset cutter in roller cone bit". in Proc. 7th Int. Conf. "LITTERIS ET ARTIBUS", Lviv, Ukraine, November 23-25, 2017, pp. 252-253.

[10] A. M. Slipchuk, and R. S. Jakum, "Doslidzhennya stiykosti reheneratsiyi «kombinovanyy zub-sharoshka» burovykh doliv na vidpovidniy 3-D modeli" ["Reseach of strength in connection «Combined tungsten carbide inset cutter-cone» of roller cone drill bit for example 3-D model"], Visnyk Natsional'noho tekhnichnoho universytetu «Kharkivs'kyy politekhnichnyy instytut». Seriya: Tekhnolohiyi $v$ mashynobuduvanni [Bulletin of the National Technical University «Kharkiv Polytechnic Institute». Series: Technologies in mechanical engineering], vol. 34 (1310), pp. 15-21, 2018. [in Ukrainian]. 